\title{
Nanofluid Flow over a Permeable Surface with Convective Boundary Conditions and Radiative Heat Transfer
}

\author{
P. K. Kameswaran, ${ }^{1}$ P. Sibanda, ${ }^{1}$ and A. S. N. Murti $^{2}$ \\ ${ }^{1}$ School of Mathematics, Statistics and Computer Science, University of KwaZulu-Natal, \\ Private Bag X01, Scottsville 3209, Pietermaritzburg, South Africa \\ ${ }^{2}$ Department of Engineering Mathematics, GITAM University GIT, Gandhi Nagar, Rushikonda, \\ Visakhapatnam Andhra Pradesh 530 045, India \\ Correspondence should be addressed to P. Sibanda; sibandap@ukzn.ac.za
}

Received 24 January 2013; Revised 19 February 2013; Accepted 19 February 2013

Academic Editor: Anuar Ishak

Copyright ( $\odot 2013$ P. K. Kameswaran et al. This is an open access article distributed under the Creative Commons Attribution License, which permits unrestricted use, distribution, and reproduction in any medium, provided the original work is properly cited.

\begin{abstract}
We investigate the effects of thermal radiation and convective boundary conditions on heat and mass transfer in nanofluid flow over a permeable flat plate. The mathematical model for the nanofluid incorporates variations in the nanoparticle volume fraction of up to $20 \%$. The performance of two water-based nanofluids, namely, stable suspensions of copper and gold nanoparticles in water was investigated. The governing partial differential equations were transformed into ordinary ones using a similarity transformation and solved numerically. The numerical results were validated by comparison with previously published results in the literature. The main focus of this paper is to study the fluid and surface parameters such as the radiation parameter, and suction/injection parameter, solute concentration profiles, as well as the skin friction coefficient and heat and mass transfer rates were conducted.
\end{abstract}

\section{Introduction}

Heat and mass transfer characteristics of a Newtonian fluid flow past a vertical plate have received considerable attention in recent years because of its extensive applications in engineering processes. Forced convection over a flat plate has been widely studied from both theoretical and experimental standpoints over the past few decades. Early studies were mainly concerned with investigating the similarity solutions of boundary layer flows, particularly flow past a flat plate placed in a uniform free stream first investigated by Blasius [1]. This work was subsequently extended by many authors to explore various aspects of flow and heat transfer on flat surfaces (Pohlhausen [2], Howarth [3], Abu-Sitta [4], Wang [5], Cortell [6], and Sakiadis [7]). Mukhopadhyay et al. [8] presented a study of boundary layer flow and heat transfer over a porous moving plate in the presence of thermal radiation. They found that dual solutions existed when the plate and the fluid moved in opposite directions. In the case of a porous plate, the fluid velocity increases, whereas the temperature decreased for increasing values of the suction parameter.

Radiative heat transfer has important applications in physics and engineering including in space technology and other high-temperature processes. Thermal radiation effects may also play an important role in controlling heat transfer in manufacturing processes where the quality of the final product may depend on heat control factors. Hightemperature plasmas, the cooling of nuclear reactors, liquid metal fluids, and power generation systems are some important applications of radiative heat transfer from a vertical wall to conductive gray fluids. In high-temperature chemical operations such as in combustion and fire science, it may be necessary to simulate thermal radiation heat transfer effects in combination with conduction, convection, and mass transfer. The effect of radiation on heat transfer problems was studied by Hossain and Takhar [9]. Hamad et al. [10] studied radiation effects on heat and mass transfer in MHD stagnation-point flow over a permeable flat plate with convective surface boundary conditions and 
temperature-dependent viscosity. They observed that the convective heat transfer parameter lowers the fluid velocity and the wall heat transfer rate. Radiation, however, increases the fluid velocity, temperature, and the heat transfer rate. Singh et al. [11] studied the effects of thermophoresis on hydromagnetic mixed convection and mass transfer flow past a vertical permeable plate with variable suction and thermal radiation. They observed that thermophoresis has a dominant effect on mass transfer in particle deposition processes. Salleh et al. [12] studied free convection over a permeable horizontal flat plate embedded in a porous medium with radiation effects and mixed thermal boundary conditions. They found that the velocity and temperature decreased with an increase in the radiation parameter. A similar solution for laminar thermal boundary layer over a flat plate with a convective surface boundary condition was studied by Magyari [13]. He found that the wall temperature decreased monotonically with increasing values of $\mathrm{Pr}$ for all values of Bi. Merkin and Pop [14] studied the forced convection flow of a uniform stream over a flat surface with a convective surface boundary condition. They found that the heat transfer near the leading edge is to be dominated by the surface heat flux. The effect of transpiration on self-similar boundary layer flow over moving surfaces was studied by Weidman et al. [15].

In recent years tremendous effort has been given to the study of nanofluids. The word nanofluid describes a liquid suspension containing ultra-fine particles (diameter less than $50 \mathrm{~nm}$ ), Choi [16]. Experimental studies (Masuda et al. [17], Das et al. [18], Pak and Cho [19], and Xuan and $\mathrm{Li}[20])$ showed that even with a small volumetric fraction of nanoparticles (usually less than 5\%), the thermal conductivity of the base liquid is enhanced by $10-50 \%$ with a remarkable improvement in the convective heat transfer coefficient.

The thermophysical properties of nanofluids such as thermal conductivity, diffusivity, and viscosity have been studied by Kang et al. [21], Velagapudi et al. [22], and Rudyak et al. [23]. The flow of a nanofluid with suction or injection on a moving surface was studied by Bachok et al. [24]. They found that dual solutions exist when the surface and the free stream move in opposite directions. Their results further indicated that suction delays boundary layer separation, while injection accelerated it. Merkin [25] studied the boundary layer flow of a Newtonian fluid past a permeable static or moving flat plate. The literature on nanofluids has been reviewed by Trisaksri and Wongwises [26], Wang and Mujumdar [27], and Eastman et al. [28] among several others. The unsteady stagnation-point flow in a nanofluid was investigated by Bachok et al. [29]. They found that the inclusion of nanoparticles in the water-based fluid produced an increase in the skin friction and heat transfer coefficients. Bachok et al. [30] studied the stagnation-point flow and heat transfer over an exponentially stretching/shrinking sheet in a nanofluid. They observed that the skin friction coefficient and the local Nusselt number are higher for a $\mathrm{Cu}$-water nanofluid compared to those for $\mathrm{Al}_{2} \mathrm{O}_{3}$ and $\mathrm{TiO}_{2}$ nanoparticles. Bachok et al. [31] investigated flow and heat transfer characteristics on a moving plate in a nanofluid. They observed that reduced thermal diffusivity leads to higher temperature gradients and, therefore, enhanced heat transfer. These studies were subsequently extended by the authors ( Bachok et al. [32], Bachok et al. [33], Bachok et al. [34], Bachok et al. [35], and Bachok et al. [36]) to various aspects of heat transfer mechanisms on various flow geometries.

The objective of this paper is to discuss the effects of various material and physical parameters such as thermal radiation and nanoparticle volume fraction on heat and mass transfer characteristics in two water-based nanofluids with suction/injection and radiation and solute concentration. The momentum and energy equations are coupled and nonlinear. By using suitable similarity variables these equations are converted into coupled ordinary differential equations and solved numerically. This work has not been considered previously in the literature.

\section{Mathematical Formulation}

Consider steady, incompressible two-dimensional nanofluid flow over a vertical flat plate. The coordinate system is chosen such that $x$ measures the distance along the plate and $y$ is the distance normal to it. The ambient temperature $T$ and solute concentration $C$ are denoted by $T_{\infty}$ and $C_{\infty}$, respectively. The fluid is a water-based nanofluid containing either copper $\mathrm{Cu}$ or gold $\mathrm{Au}$ nanoparticles. The base fluid and the nanoparticles are in thermal equilibrium. Under these assumptions, the boundary layer equations governing the flow, heat, and concentration fields are (Tiwari and Das [37])

$$
\begin{gathered}
\frac{\partial u}{\partial x}+\frac{\partial v}{\partial y}=0 \\
u \frac{\partial u}{\partial x}+v \frac{\partial u}{\partial y}=\frac{\mu_{n f}}{\rho_{n f}} \frac{\partial^{2} u}{\partial y^{2}}, \\
u \frac{\partial T}{\partial x}+v \frac{\partial T}{\partial y}=\alpha_{n f} \frac{\partial^{2} T}{\partial y^{2}}-\frac{1}{\left(\rho C_{p}\right)} \frac{\partial q_{r}}{\partial y}, \\
u \frac{\partial C}{\partial x}+v \frac{\partial C}{\partial y}=D \frac{\partial^{2} C}{\partial y^{2}} .
\end{gathered}
$$

The boundary conditions for (1)-(4) are assumed in the form:

$$
\begin{gathered}
u=0, \quad v=V_{w}(x), \quad-k_{f} \frac{\partial T}{\partial y}=h_{f}\left(T_{f}-T\right), \\
C=C_{w} \quad \text { at } y=0, \\
u \longrightarrow U_{\infty}, \quad T \longrightarrow T_{\infty}, \quad C \longrightarrow C_{\infty} \quad \text { as } y \longrightarrow \infty,
\end{gathered}
$$

where $u, v$ are the velocity components in the $x$ and $y$ directions, respectively, $\rho$ is the density, $C_{p}$ is the specific heat at constant pressure, $q_{r}$ is the radiative heat flux, $D$ is the species diffusivity, $V_{w}(x)$ is the velocity at the surface of the plate with $V_{w}(x)>0$ for injection, $V_{w}(x)<0$ for suction, and $V_{w}(x)=0$ corresponds to an impermeable plate. The injection/suction velocity is defined as

$$
V_{w}(x)=-\frac{1}{2} \sqrt{\frac{U_{\infty} \nu_{f}}{x}} f_{w},
$$


where $f_{w}$ is a constant that determines the transpiration rate at the surface with $f_{w}>0$ for suction, $f_{w}<0$ for injection, and $f_{w}=0$ corresponding to an impermeable surface.

At the bottom surface of the plate the fluid is heated via convection from a hot fluid of temperature $T_{f}$ and heat transfer coefficient $h_{f}$. Here $h_{f}$ is proportional to $x^{-1 / 2}$, that is, $h_{f}=c x^{-1 / 2}$, where $c$ is a constant. Following Rosseland's approximation the radiative heat flux $q_{r}$ is modeled as

$$
q_{r}=-\frac{4 \sigma^{*}}{3 k^{*}} \frac{\partial T^{4}}{\partial y}
$$

where $\sigma^{*}$ is the Stefan-Boltzman constant and $k^{*}$ is the mean absorption coefficient. Assuming that the temperature differences within the flow are sufficiently small, then $T^{4}$ may be expressed as a linear function $T^{4} \equiv 4 T_{\infty}^{3} T-3 T_{\infty}^{4}$ and

$$
\frac{\partial q_{r}}{\partial y}=-\frac{16 \sigma^{*} T_{\infty}^{3}}{3 k^{*}} \frac{\partial^{2} T}{\partial y^{2}}
$$

The effective dynamic viscosity of the nanofluid was given by Brinkman [38] as

$$
\mu_{n f}=\frac{\mu_{f}}{(1-\phi)^{2.5}}
$$

where $\phi$ is the solid volume fraction of nanoparticles. The effective density of the nanofluids is given as

$$
\rho_{n f}=(1-\phi) \rho_{f}+\phi \rho_{s} .
$$

The thermal diffusivity of the nanofluid is

$$
\alpha_{n f}=\frac{k_{n f}}{\left(\rho C_{p}\right)_{n f}}
$$

where the heat capacitance of the nanofluid is given by

$$
\left(\rho C_{p}\right)_{n f}=(1-\phi)\left(\rho C_{p}\right)_{f}+\phi\left(\rho C_{p}\right)_{s}
$$

The thermal conductivity of nanofluids restricted to spherical nanoparticles is approximated by the MaxwellGarnetss (MG) model (see Maxwell-Garnett [39] and Guérin et al. [40]):

$$
k_{n f}=k_{f}\left[\frac{k_{s}+2 k_{f}-2 \phi\left(k_{f}-k_{s}\right)}{k_{s}+2 k_{f}+\phi\left(k_{f}-k_{s}\right)}\right] .
$$

Here, the subscripts $n f, f$, and $s$ represent the thermophysical properties of the nanofluid, base fluid, and nanosolid particles, respectively. The continuity equation (1) is satisfied by introducing a stream function $\psi(x, y)$ such that

$$
u=\frac{\partial \psi}{\partial y}, \quad v=-\frac{\partial \psi}{\partial x},
$$

where $\psi=\left(U_{\infty} \nu_{f} x\right)^{1 / 2} f(\eta), f(\eta)$ is the dimensionless stream function, and $\eta=\left(U_{\infty} / \nu_{f} x\right)^{1 / 2} y$.
The velocity components are then given by

$$
u=U_{\infty} f^{\prime}(\eta), \quad v=\frac{1}{2}\left(\frac{U_{\infty} \nu_{f}}{x}\right)^{1 / 2}\left[\eta f^{\prime}(\eta)-f(\eta)\right] .
$$

The temperature and solute concentrations are represented as

$$
\begin{aligned}
& T=T_{\infty}+\left(T_{f}-T_{\infty}\right) g(\eta), \\
& C=C_{\infty}+\left(C_{w}-C_{\infty}\right) h(\eta),
\end{aligned}
$$

where $g(\eta)$ is the dimensionless temperature and $h(\eta)$ is the dimensionless solute concentration. On using (7)-(16), (2)(5) transform into the following two-point boundary value problem:

$$
\begin{gathered}
f^{\prime \prime \prime}+\frac{1}{2} \phi_{1} f f^{\prime \prime}=0, \\
\left(1+\frac{4}{3 N_{R}}\right) g^{\prime \prime}+\frac{1}{2} \operatorname{Pr}\left(\frac{k_{f}}{k_{n f}}\right) \phi_{2} f g^{\prime}=0, \\
h^{\prime \prime}+\frac{1}{2} S c f h^{\prime}=0, \\
f(0)=f_{w}, \quad f^{\prime}(0)=0, \quad f^{\prime}(\infty) \longrightarrow 1, \\
g^{\prime}(0)=-\operatorname{Bi}(1-g(0)), \quad g(\infty) \longrightarrow 0, \\
h(0)=1, \quad h(\infty) \longrightarrow 0 .
\end{gathered}
$$

The nondimensional constants in (17)-(21) are the radiation parameter $N_{R}$, the Prandtl number Pr, the Schmidt number Sc, and the Biot number Bi which is used in heat transfer calculations. They are respectively defined as

$$
\begin{gathered}
N_{R}=\frac{k_{n f} k^{*}}{4 \sigma^{*} T_{\infty}^{3}}, \quad \operatorname{Pr}=\frac{v_{f}\left(\rho C_{p}\right)_{f}}{k_{f}}, \\
\mathrm{Sc}=\frac{v_{f}}{D}, \quad \mathrm{Bi}=\frac{c}{k_{f}} \sqrt{\frac{v_{f}}{U_{\infty}}},
\end{gathered}
$$

where

$$
\begin{gathered}
\phi_{1}=(1-\phi)^{2.5}\left[1-\phi+\phi\left(\frac{\rho_{s}}{\rho_{f}}\right)\right], \\
\phi_{2}=1-\phi+\phi \frac{\left(\rho_{C p}\right)_{s}}{\left(\rho_{C p}\right)_{f}} .
\end{gathered}
$$

The thermophysical properties of the nanofluid are given in Table 1 (see Oztop and Abu-Nada [41], Alloui et al. [42]).

\section{Skin Friction, Heat and Mass Transfer Coefficients}

In addition to the velocity and temperature, the quantities of engineering interest in heat and mass transport problems 


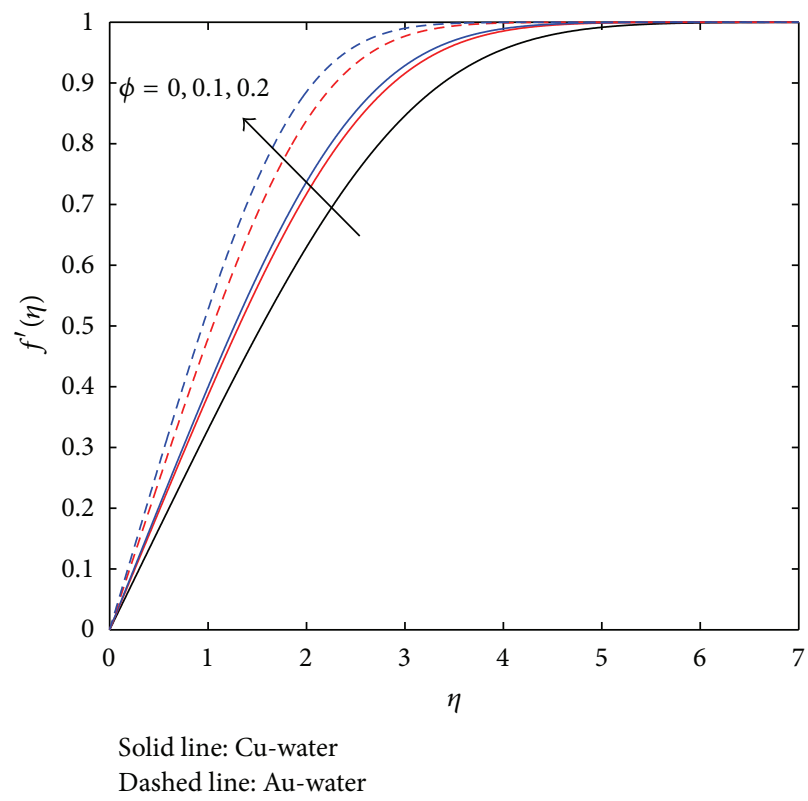

(a)

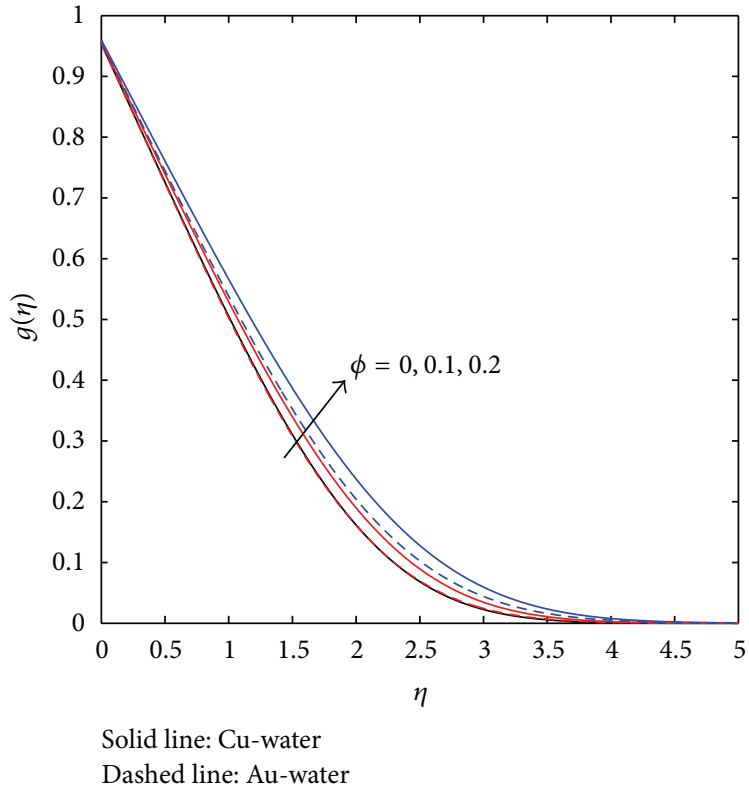

(b)

FIGURE 1: Effects of the nanoparticle volume fraction $\phi$ on (a) velocity and (b) temperature profiles, when $f_{w}=0, \mathrm{Bi}=10, N_{R}=1$, and $\mathrm{Sc}=1.5$.

TABLE 1: Thermophysical properties of water and nanoparticles.

\begin{tabular}{lcccc}
\hline Properties $\rightarrow$ & $\rho\left(\mathrm{kg} / \mathrm{m}^{3}\right)$ & $C_{p}(\mathrm{~J} / \mathrm{kgK})$ & $k(\mathrm{~W} / \mathrm{mK})$ & $\beta \times 10^{5}\left(\mathrm{~K}^{-1}\right)$ \\
\hline Pure water & 997.1 & 4179 & 0.613 & 21 \\
$\mathrm{Cu}$ & 8933 & 385 & 401 & 1.67 \\
$\mathrm{Au}$ & 19282 & 129 & 310 & - \\
\hline
\end{tabular}

are the skin friction coefficient $C_{f}$, the local Nusselt number $\mathrm{Nu}_{x}$, and the local Sherwood number $\mathrm{Sh}_{x}$. These parameters, respectively, characterize the surface drag and wall heat transfer rates. The shearing stress at the surface $\tau_{w}$ is given by

$$
\tau_{w}=-\mu_{n f}\left[\frac{\partial u}{\partial y}\right]_{y=0}=-\frac{\mu_{f}}{(1-\phi)^{2.5}} U_{\infty} \sqrt{\frac{U_{\infty}}{v_{f} x}} f^{\prime \prime}(0),
$$

where $\mu_{n f}$ is the coefficient of viscosity. The skin friction coefficient is defined as

$$
C_{f}=\frac{2 \tau_{w}}{\rho_{f} u_{\infty}^{2}}
$$

and using (25) in (26) we obtain

$$
C_{f}(1-\phi)^{2.5} \sqrt{\operatorname{Re}_{x}}=-2 f^{\prime \prime}(0) .
$$
by

The heat transfer rate at the surface flux at the wall is given

$$
q_{w}=-k_{n f}\left[\frac{\partial T}{\partial y}\right]_{y=0}=-k_{n f}\left(T_{f}-T_{\infty}\right) \sqrt{\frac{U_{\infty}}{v_{f} x}} g^{\prime}(0),
$$

where $k_{n f}$ is the thermal conductivity of the nanofluid. The Nusselt number is defined as

$$
\mathrm{Nu}_{x}=\frac{x}{k_{f}} \frac{q_{w}}{T_{f}-T_{\infty}} .
$$

Using (28) in (29) the dimensionless wall heat transfer rate is obtained as mentioned later

$$
\frac{\mathrm{Nu}_{x}}{\sqrt{\mathrm{Re}_{x}}}\left(\frac{k_{f}}{k_{n f}}\right)=-g^{\prime}(0) .
$$

The mass flux at the surface of the wall is given by

$$
J_{w}=-D\left[\frac{\partial C}{\partial y}\right]_{y=0}=-D\left(C_{w}-C_{\infty}\right) \sqrt{\frac{U_{\infty}}{v_{f} x}} h^{\prime}(0),
$$

and the Sherwood number is defined as

$$
\mathrm{Sh}_{x}=\frac{x}{D} \frac{J_{w}}{C_{w}-C_{\infty}} .
$$

Using (31) in (32) the dimensionless wall mass transfer rate is obtained as

$$
\frac{\mathrm{Sh}_{x}}{\sqrt{\mathrm{Re}_{x}}}=-h^{\prime}(0) .
$$

In (27), (30), and (33), $\mathrm{Re}_{x}$ represents the local Reynolds number defined by $\operatorname{Re}_{x}=x U_{\infty} / \nu_{f}$.

\section{Results and Discussion}

This study investigated the effects of radiation and nanoparticle volume fraction on heat and mass transfer on nanofluid 
TABLE 2: Comparison of wall temperature gradient $-g^{\prime}(0)$ for different values of $\mathrm{Bi}$, Pr when $f_{w}=0, \phi=0, N_{R}=10^{10}$, and $\mathrm{Sc}=0$ (impermeable surface).

\begin{tabular}{|c|c|c|c|c|c|c|}
\hline \multirow{2}{*}{$\mathrm{Bi}$} & \multicolumn{2}{|c|}{ Aziz [43] } & \multicolumn{2}{|c|}{ Ishak [44] } & \multicolumn{2}{|c|}{ Present Results } \\
\hline & $\operatorname{Pr}=0.1$ & $\operatorname{Pr}=10$ & $\operatorname{Pr}=0.1$ & $\operatorname{Pr}=10$ & $\operatorname{Pr}=0.1$ & $\operatorname{Pr}=10$ \\
\hline 0.05 & 0.0373 & 0.0468 & 0.036844 & 0.046787 & 0.036844 & 0.046787 \\
\hline 0.10 & 0.0594 & 0.0879 & 0.058338 & 0.087925 & 0.058338 & 0.087925 \\
\hline 0.20 & 0.0848 & 0.1569 & 0.082363 & 0.156903 & 0.082363 & 0.156903 \\
\hline 0.40 & 0.1076 & 0.2582 & 0.103720 & 0.258174 & 0.103720 & 0.258174 \\
\hline 0.60 & 0.1182 & 0.3289 & 0.113533 & 0.328945 & 0.113533 & 0.328945 \\
\hline 0.80 & 0.1243 & 0.3812 & 0.119170 & 0.381191 & 0.119170 & 0.381191 \\
\hline 1 & 0.1283 & 0.4213 & 0.122830 & 0.421344 & 0.122830 & 0.421344 \\
\hline 5 & 0.1430 & 0.6356 & 0.136215 & 0.635583 & 0.136215 & 0.635583 \\
\hline 10 & 0.1450 & 0.6787 & 0.138096 & 0.678721 & 0.138096 & 0.678721 \\
\hline 20 & 0.1461 & 0.7026 & 0.139056 & 0.702563 & 0.139056 & 0.702563 \\
\hline
\end{tabular}

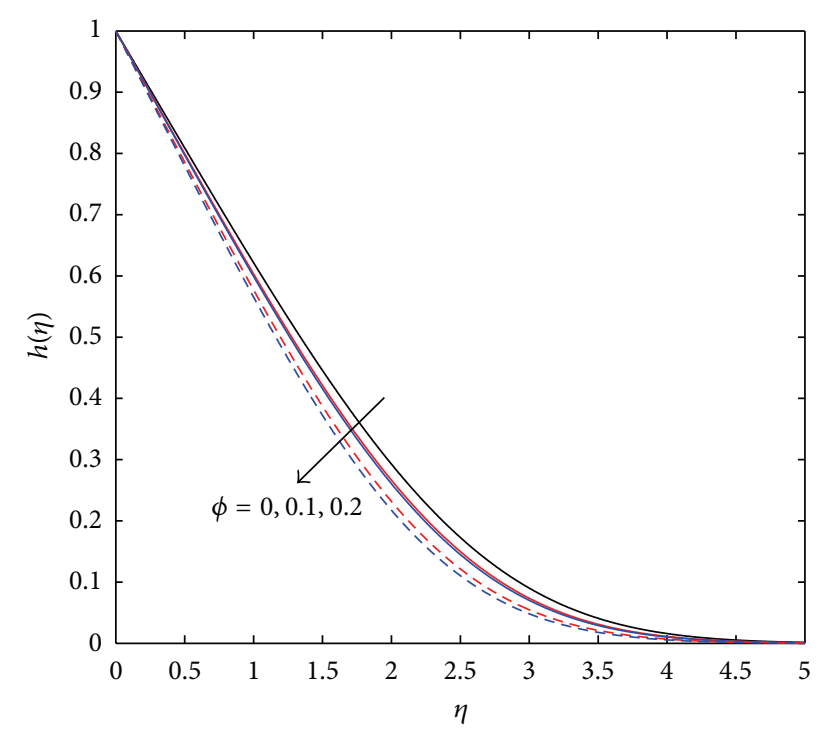

Solid line: Cu-water

Dashed line: Au-water

FigURE 2: Effects of the nanoparticle volume fraction $\phi$ on concentration profiles when $f_{w}=0, \mathrm{Bi}=10, N_{R}=1$, and $\mathrm{Sc}=1.5$.

flow over a permeable flat surface. We considered two different nanoparticles, copper $\mathrm{Cu}$ and gold $\mathrm{Au}$, with water as the base fluid. The Prandtl number of the base fluid (water) was kept at constant $\operatorname{Pr}=6.7850$.

The nonlinear differential equations (17)-(19) with boundary conditions (20)-(22) do not have a closed form solution. The equations were solved numerically using the Matlab bvp4c function. To check the accuracy of the solutions, the local Nusselt number $g^{\prime}(0)$ for a clear fluid is compared with results reported by Aziz [43] and Ishak [44] in Table 2. From Table 2 we observe that the values of the wall temperature gradient for different values of $\mathrm{Bi}$ and $\operatorname{Pr}$ when $f_{w}=0, \phi=0$, $N_{R}=10^{10}$, and Sc $=0$ are in good agreement with results in the literature.
Figures 1 and 2 show the effect of nanoparticle volume fraction on the velocity, temperature, and concentration profiles, respectively, in the case of $\mathrm{Cu}$-water nanofluid. From Figure 1(a), it is clear that as the nanoparticle volume fraction $\phi$ increases, the nanofluid velocity profiles width decreases (became narrower) and vice versa. Increasing the volume fraction of nanoparticles increases the thermal conductivity of the nanofluid, and we observe a thickening of the thermal boundary layer. We also observe that in the dynamic boundary layer, the gradient of the velocity from wall to the free stream is more rapid when $\phi$ is increased. The same trend is observed in the case of a Au-water nanofluid. We also found that the axial velocity in a Au-water nanofluid is relatively smaller than that of a $\mathrm{Cu}$-water nanofluid.

Figures 1(b) and 2 illustrate the effect of nanoparticle volume fraction on the temperature and concentration profiles, respectively. It is clear that as the nanoparticle volume fraction increases the nanofluid temperature increases. The conductivity of the nanofluid increases as the nanoparticle volume fraction increases leading to a broadening of the thermal boundary layer profiles, see Hady et al. [45]. Since the thermal conductivity of $\mathrm{Cu}$ is higher than that of $\mathrm{Au}$, we observe that the profiles for a $\mathrm{Cu}$-water nanofluid are proportionally broader than those of a Ag-water nanofluid. In addition, we note that the solute concentration decreases with an increase in the nanoparticle volume fraction for both Ag-water and $\mathrm{Cu}$-water nanofluids.

The variation of the skin friction coefficient, wall heat, and mass transfer rates with the suction/injection parameter $f_{w}$ for different nanoparticle volume fractions $\phi$ is shown in Figures 3 and 4 . We note that the inclusion of nanoparticles into the base fluid increases the skin friction coefficient. We also observe that skin friction coefficient increases as the nanoparticle volume fraction increases and that the increment is more pronounced in the case of a Au-water nanofluid as compared to a $\mathrm{Cu}$-water nanoparticle. The same trend is observed in the case of the mass transfer coefficient. Figure 3(b) shows that the lowest heat transfer rate is obtained for $\mathrm{Au}$ nanoparticles due to the domination of 


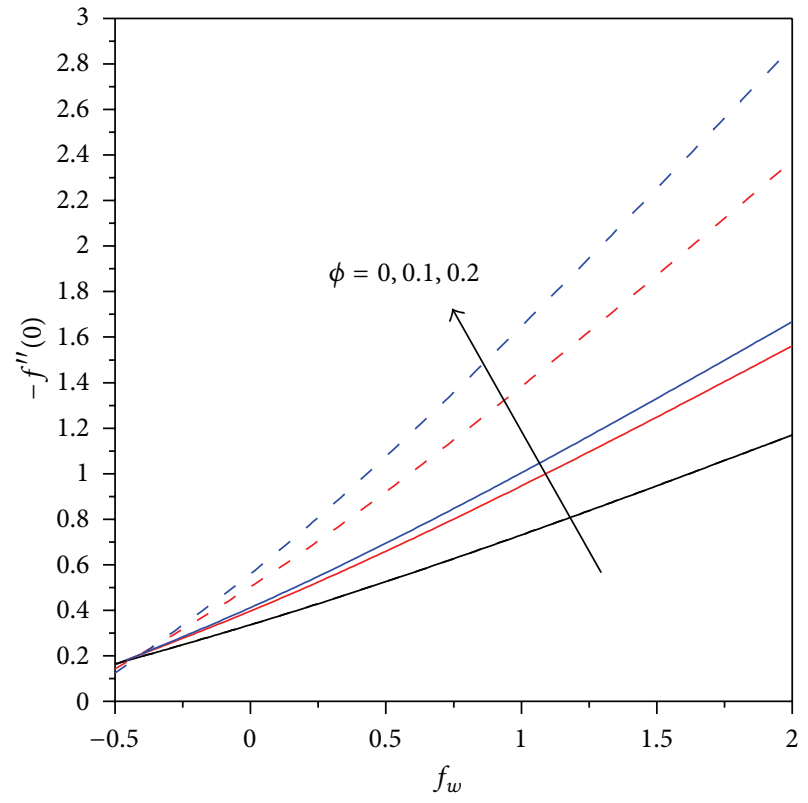

Solid line: $\mathrm{Cu}$-water

Dashed line: Au-water

(a)

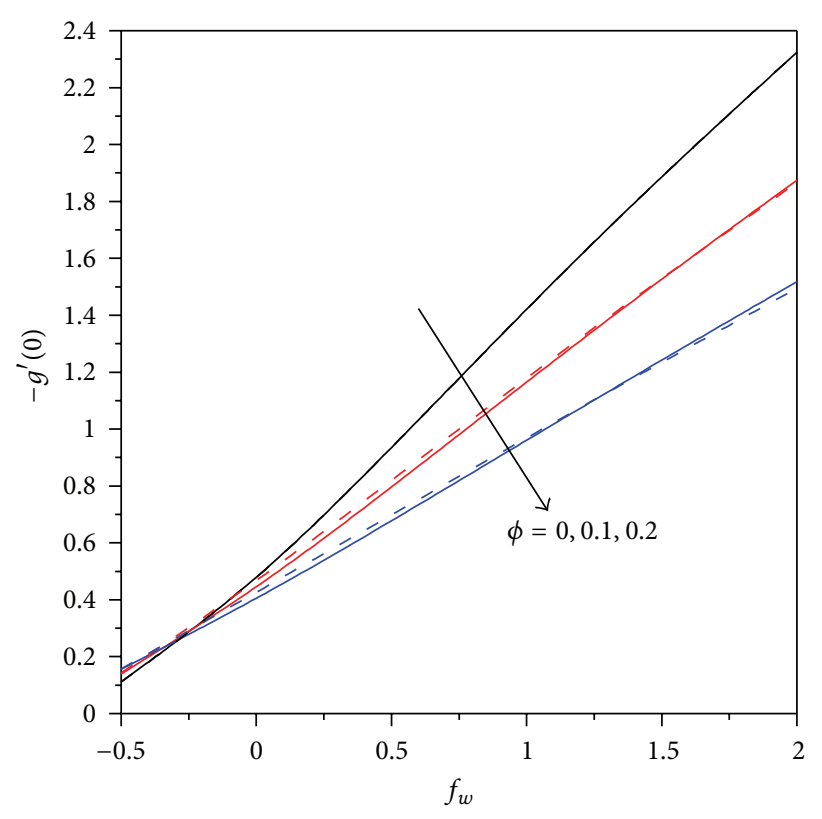

Solid line: $\mathrm{Cu}$-water Dashed line: $\mathrm{Au}$-water

(b)

FIGURE 3: Effects of suction/injection parameter $f_{w}$ on (a) skin friction and (b) heat transfer coefficient, when $N_{R}=1, \mathrm{Bi}=10$, and $\mathrm{Sc}=1.5$.

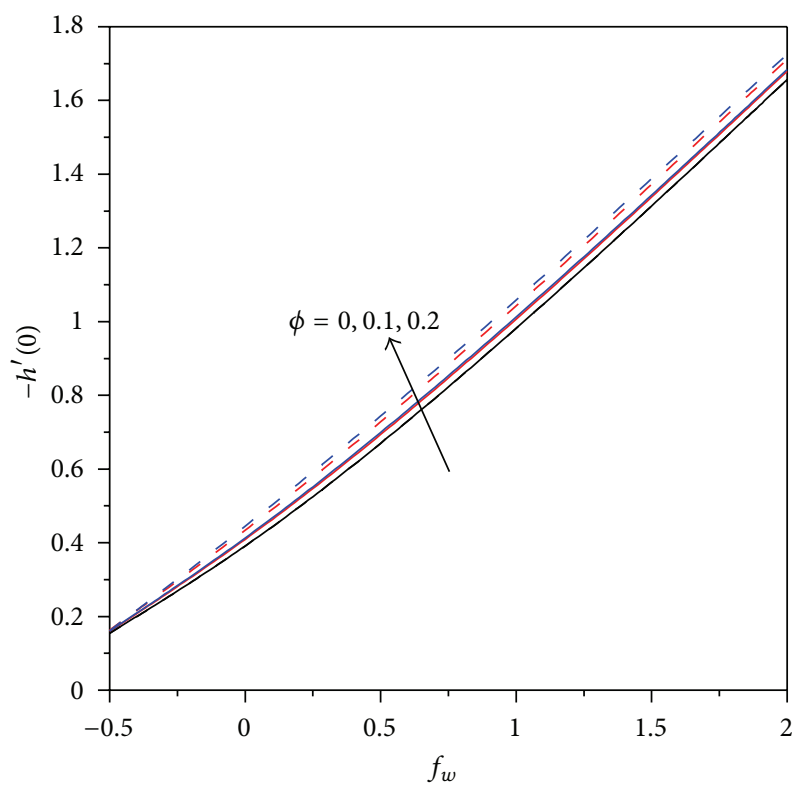

Solid line: $\mathrm{Cu}$-water

Dashed line: Au-water

FIGURE 4: Effects of suction/injection parameter $f_{w}$ on mass transfer coefficient, when $N_{R}=1, \mathrm{Bi}=10$, and $\mathrm{Sc}=1.5$.

the conduction mode of heat transfer. This is due to a lower thermal conductivity of Au nanoparticles compared with $\mathrm{Cu}$ nanoparticles.
Figures 5 and 6 show the velocity, temperature, and concentration distributions for different values of the suction or injection parameter $f_{w}$. The parameter Bi has no influence on the flow field, which is also clear from (17)-(22). We note that the velocity gradient at the surface, which is proportional to the skin friction coefficient, increases with increasing $f_{w}$ for both nanofluids. Thus the surface shear stress is higher for suction $\left(f_{w}>0\right)$ compared to injection $\left(f_{w}<0\right)$. We also observe that for all values of $f_{w}$ the radial velocity $f^{\prime}(\eta)$ attains a maximum value close to the surface of the wall and decreases monotonically along the boundary layer for both nanofluids. Figures 5(b) and 6 show that the temperature and concentration profiles at the surface are higher for suction compared to those for injection in the case of a $\mathrm{Cu}$-water nanofluid. This is due to the fact that the surface shear stress increases when suction is introduced, which in turn increases the local Nusselt number. We note that the lowest heat transfer rate is obtained in the case of Au nanoparticles due to the domination of the conduction mode of heat transfer. This is due to the fact that $\mathrm{Au}$ nanoparticles have a lower value of thermal conductivity compared to $\mathrm{Cu}$ nanoparticles. These findings are similar to the results obtained by Ishak [44] in the case of newtonian fluids $(\phi=0)$.

The effects of thermal radiation $N_{R}$ and the Biot number $\mathrm{Bi}$ on the temperature profiles are shown in Figure 7. The temperature decreases as the thermal radiation increases. This in turn leads to an increase in the heat transfer rate, Hady et al. [45]. The drop in the temperature is higher for a $\mathrm{Au}$-water nanofluid compared to a $\mathrm{Cu}$-water nanofluid, and $\mathrm{Cu}$ nanoparticles have higher temperature distribution values than the Au nanoparticles. 


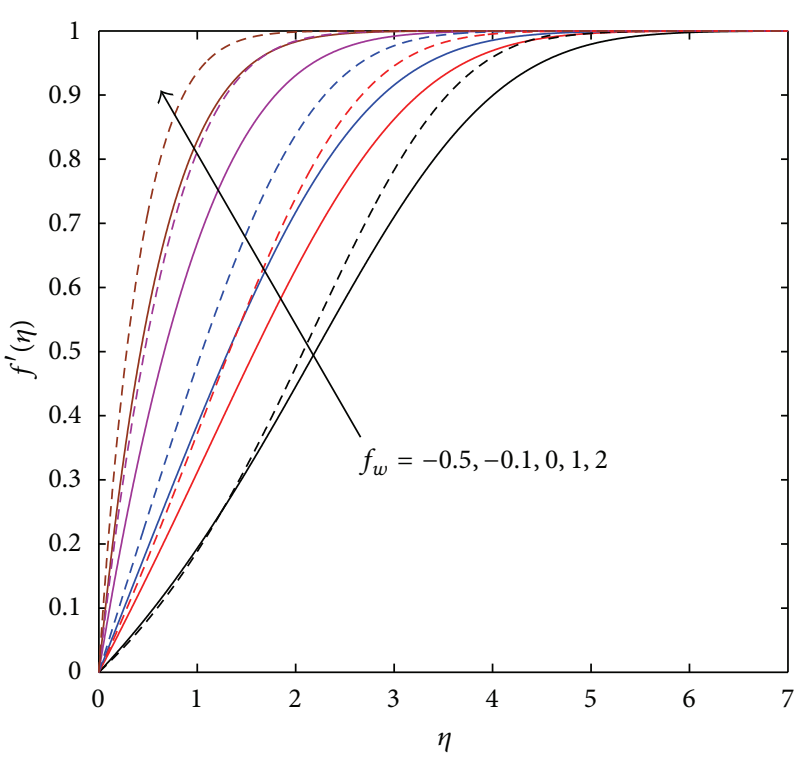

Solid line: $\mathrm{Cu}$-water Dashed line: Au-water

(a)

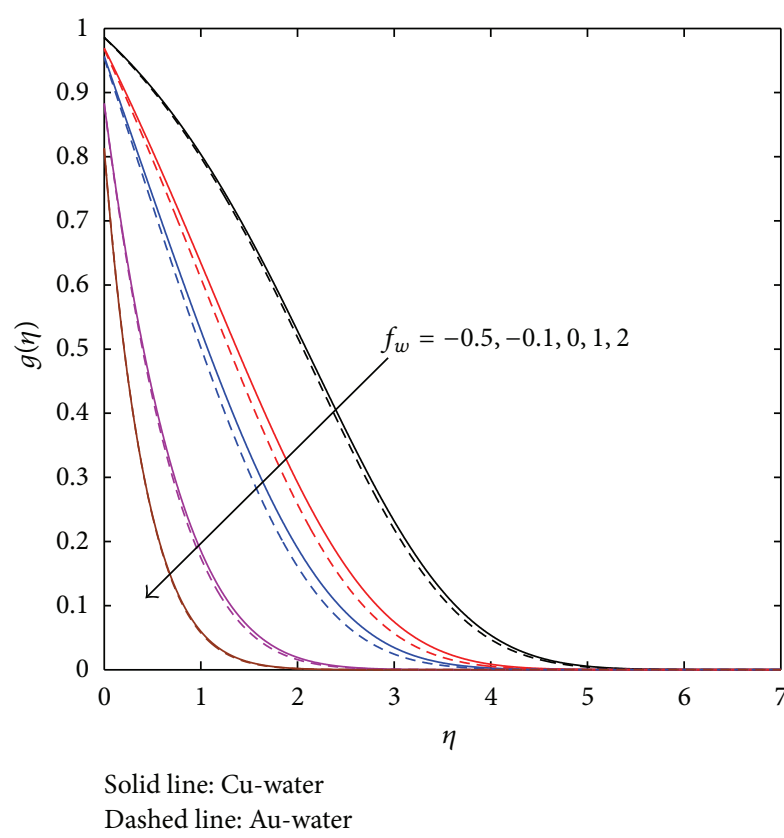

(b)

FIGURE 5: Effects of suction/injection parameter $f_{w}$ on (a) velocity and (b) temperature profiles, when $\phi=0.1, \mathrm{Bi}=10, N_{R}=1$, and $\mathrm{Sc}=1.5$.

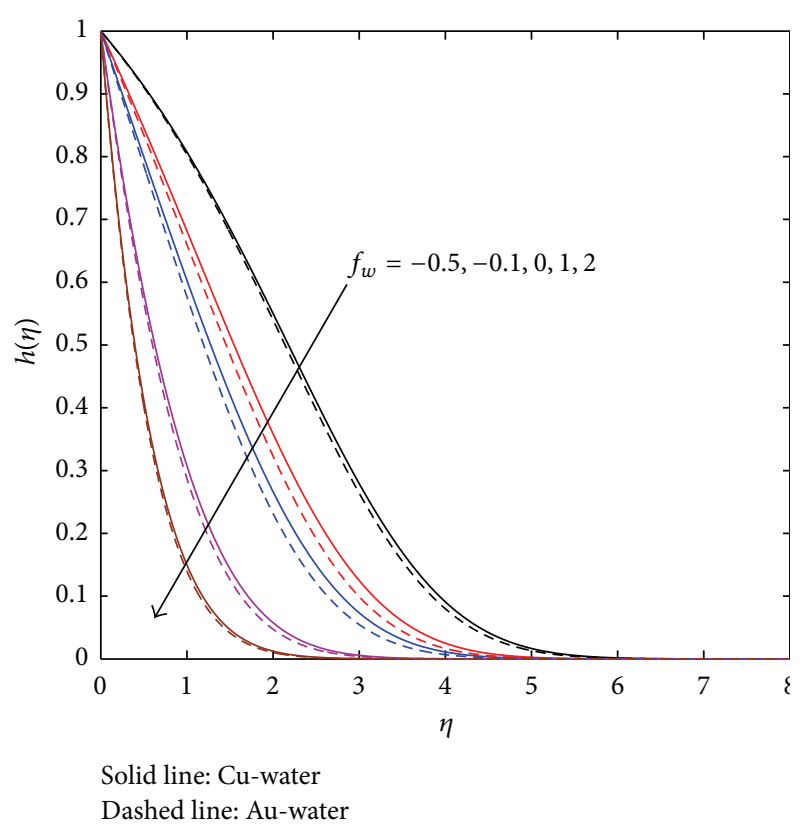

FIGURE 6: Effects of suction/injection parameter $f_{w}$ on concentration, when $\phi=0.1, \mathrm{Bi}=10, N_{R}=1$ and $\mathrm{Sc}=1.5$.

The temperature profiles for different values of the Biot number are shown in Figure 7(b). The temperature profiles for a clear fluid (when $\operatorname{Pr}=0.72$ and $f_{w}=1$ ) match with the results obtained by Aziz [43]. The surface temperature increases with $\mathrm{Bi}$ for both nanofluids. The parameter $\mathrm{Bi}$ is directly proportional to the heat transfer coefficient associated with the hot fluid $h_{f}$. The thermal resistance on the hot fluid side is inversely proportional to $h_{f}$. Thus as Bi increases, the hot fluid side convection resistance decreases, and consequently, the surface temperature increases.

Figures 8,9 , and 10 show the behaviour of the heat and mass transfer rates under the influence of $N_{R}, \mathrm{Bi}$, and $\mathrm{Sc}$, respectively, for the two different nanofluids when $\operatorname{Pr}=$ 6.7850 and $\phi=0,0.1$, and 0.2 . The change in the heat transfer rate is important in cooling and heating processes. Figures 8 and 9 show that an increase in the thermal radiation parameter and Biot number reduces the heat transfer rate. Figure 10 shows that by increasing the Schmidt numbers and solid volume fraction, the mass transfer rate increases for both nanofluids, and this increment is more in the case of $\mathrm{Au}$ nanoparticles compared to $\mathrm{Cu}$ nanoparticles.

The temperature profiles for various physical parameters in the case $\mathrm{Bi} \rightarrow \infty$ (i.e., $g(0)=1$ ) are displayed in Figures $11-13$. We note, from the convective boundary conditions (21), that $g(\eta) \rightarrow 1$ as $\mathrm{Bi} \rightarrow \infty$. The convective parameter $\mathrm{Bi}$ has no influence on the flow field. We observe further that, as the nanoparticle volume fraction increases, the nanofluid temperature increases which is consistent with expected physical behaviour and may be attributed to the fact that as the thermal conductivity of the nanofluid increases, thermal boundary layer also increases. The temperature profiles for various suction/injection parameter values are shown in Figure 12. We observe that heat transfer rate at the surface is higher in the case of suction compared to injection due to an increase in the shear stress when suction is introduced in the case of a $\mathrm{Cu}$-water nanofluid. The same trend is 


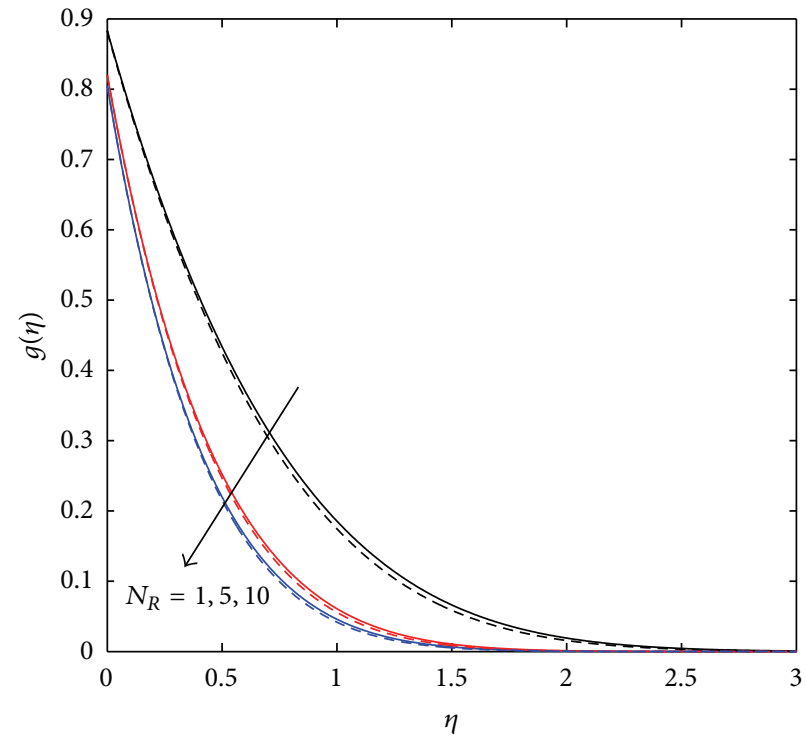

Solid line: $\mathrm{Cu}$-water Dashed line: Au-water

(a)

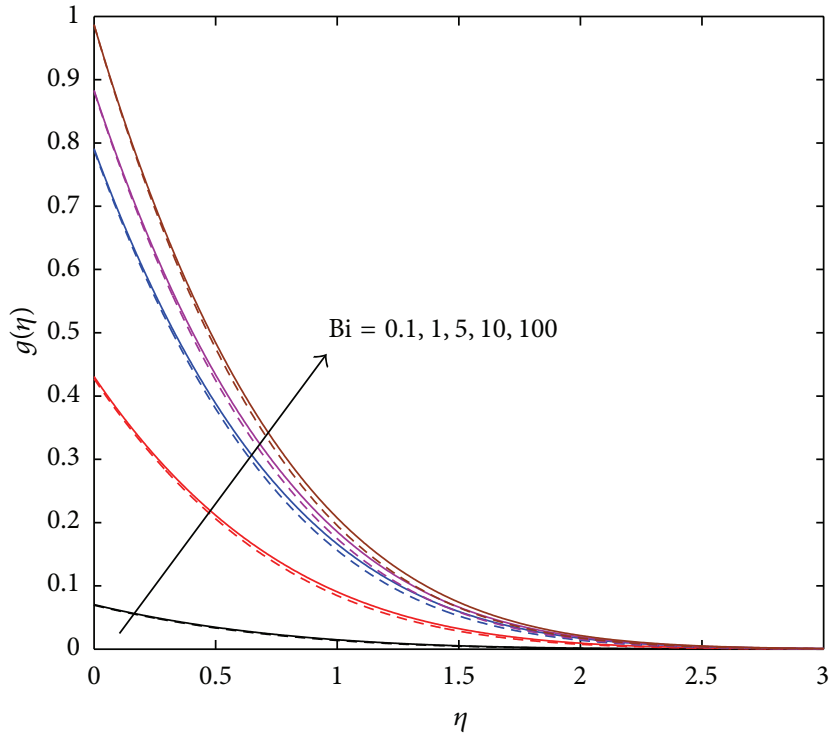

Solid line: $\mathrm{Cu}$-water Dashed line: Au-water

FIGURE 7: Effects of (a) thermal radiation $N_{R}$, when $\mathrm{Bi}=10$ and (b) effects of $\mathrm{Bi}$, when $N_{R}=1$ on temperature for various values of $\phi=0.1$, $f_{w}=1$, and $\mathrm{Sc}=1.5$.

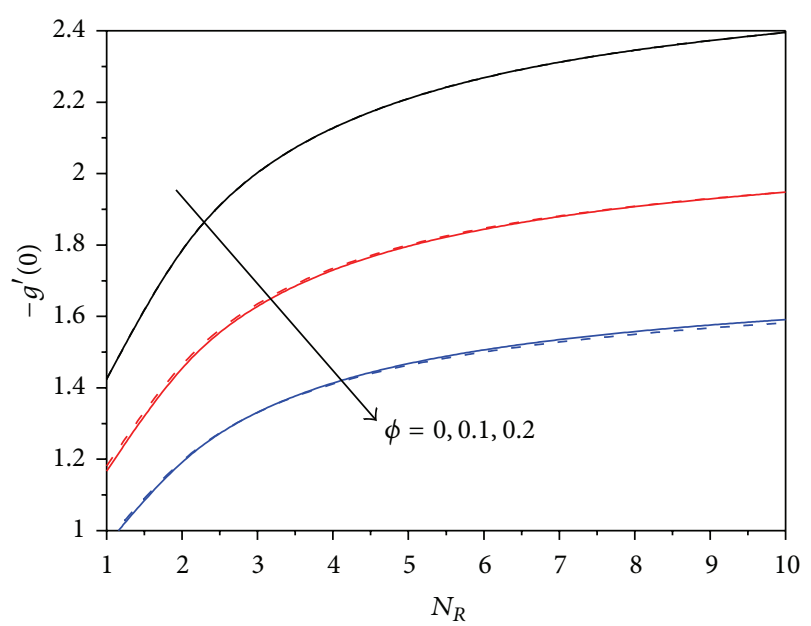

Solid line: $\mathrm{Cu}$-water Dashed line: Au-water

FIGURE 8: Effects of thermal radiation parameter $N_{R}$ on heat transfer rate, when $f_{w}=1, \mathrm{Bi}=1$, and $\mathrm{Sc}=1.5$.

observed in the case of Au nanoparticles, but the change in the temperature is less significant than for $\mathrm{Cu}$ nanoparticles due to differences in thermal conductivity.

Figure 13 shows the effect of the radiation parameter on the temperature profile. An increase in the radiation parameter reduces the thermal boundary layer thickness across the plate. The temperature $g(\eta)$ decreases as the radiation parameter $N_{R}$ increases. This may be explained by

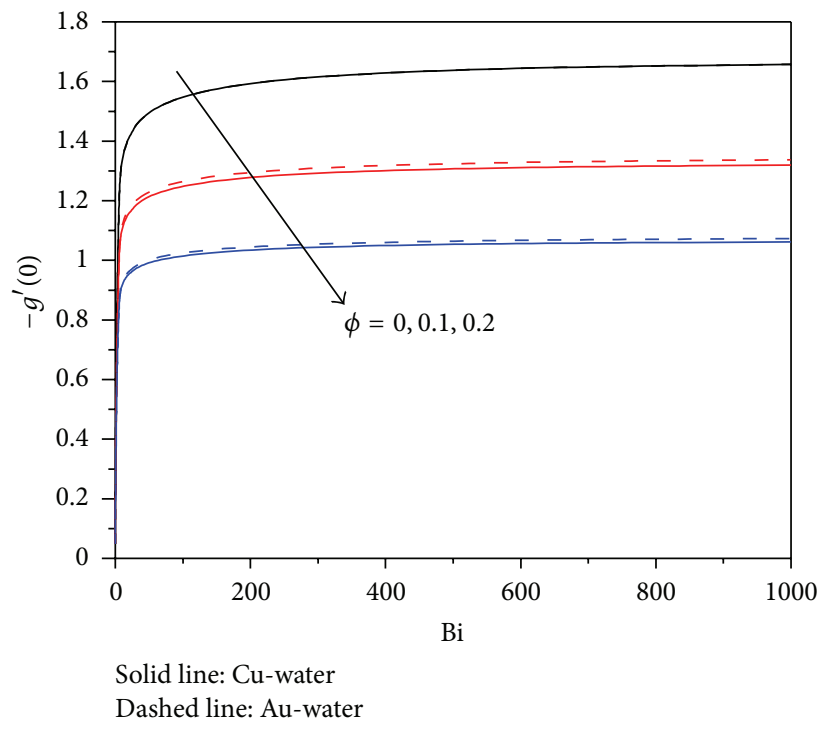

FIGURE 9: Effects of Bi on heat transfer rate, when $f_{w}=1, N_{R}=1$, and $\mathrm{Sc}=1.5$.

the fact that a decrease in the radiation parameter $N_{R}=$ $k_{n f} k^{*} / 4 \sigma^{*} T_{\infty}^{3}$ for given $k^{*}$ and $T_{\infty}$ implies a decrease in the Rosseland radiation absorptivity. The same trend is observed for both $\mathrm{Cu}$ and $\mathrm{Au}$ nanoparticles. It was also observed that the change in temperature profiles in the case of $\mathrm{Au}$-water nanofluid was slightly less significant than for a $\mathrm{Cu}$-water nanofluid. 


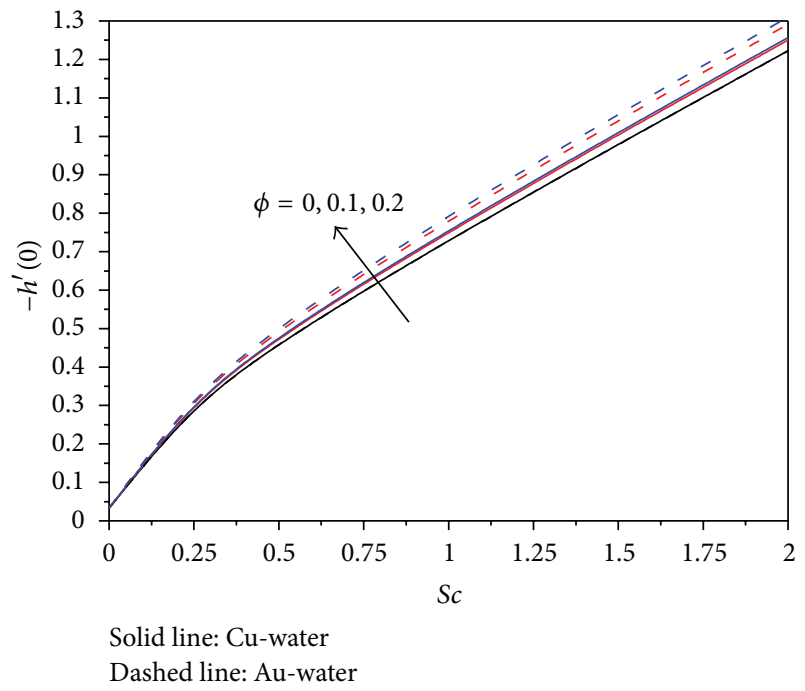

Figure 10: Effects of Sc on mass transfer rate, when $f_{w}=1, N_{R}=1$, and $\mathrm{Bi}=10$

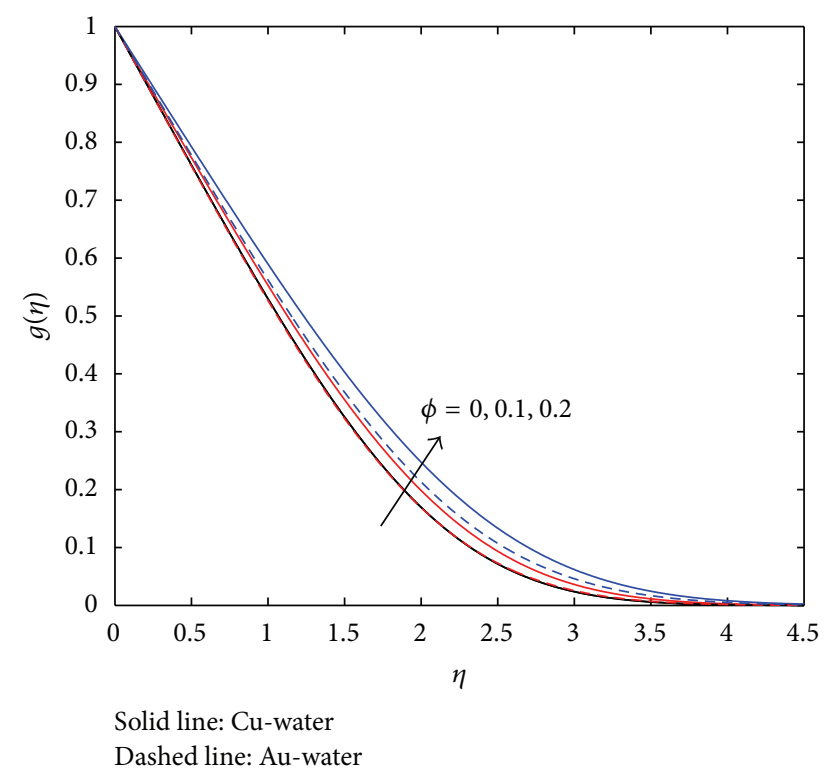

FigURE 11: Effects of $\phi$ on temperature, when $f_{w}=0, N_{R}=1, \mathrm{Sc}=$ 1.5 , and $\mathrm{Bi} \rightarrow \infty$.

\section{Conclusions}

The effects of thermal radiation on heat and mass transfer in a nanofluid flow over a permeable flat plate were studied. The governing equations were transformed into a set of coupled nonlinear differential equations and solved by using the Matlab bvp4c ODE Solver. The results were compared for selected values of the governing physical parameters with results available in the literature. We found that the velocity gradient at the surface increases with increasing $f_{w}$ for both nanofluids considered. The surface temperature increases as Biot number increases for both nanofluids.

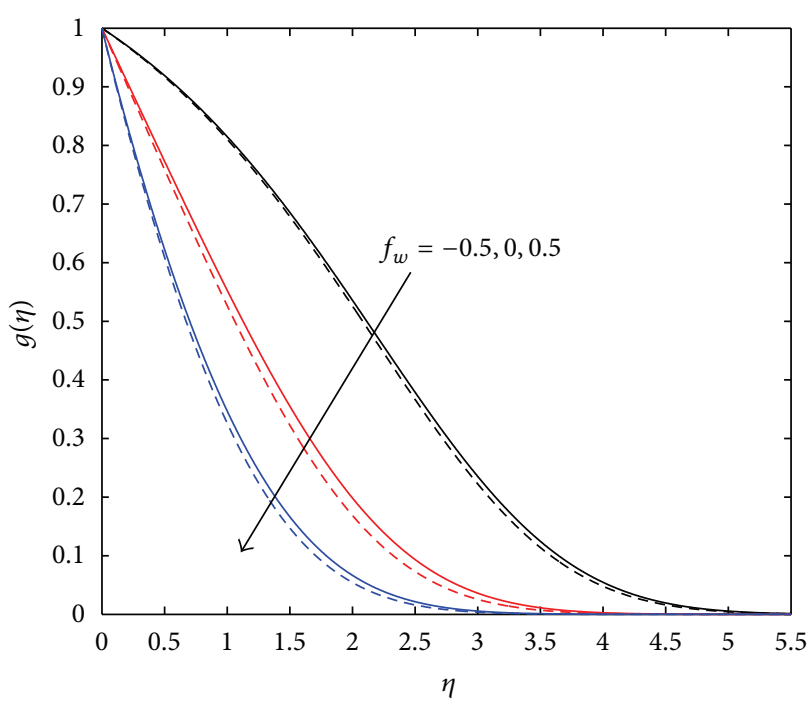

Solid line: $\mathrm{Cu}$-water Dashed line: $\mathrm{Au}$-water

FIGURE 12: Effects of suction/injection parameter $f_{w}$ on temperature, when $N_{R}=1, \mathrm{Sc}=1.5, \phi=0.1$, and $\mathrm{Bi} \rightarrow \infty$.

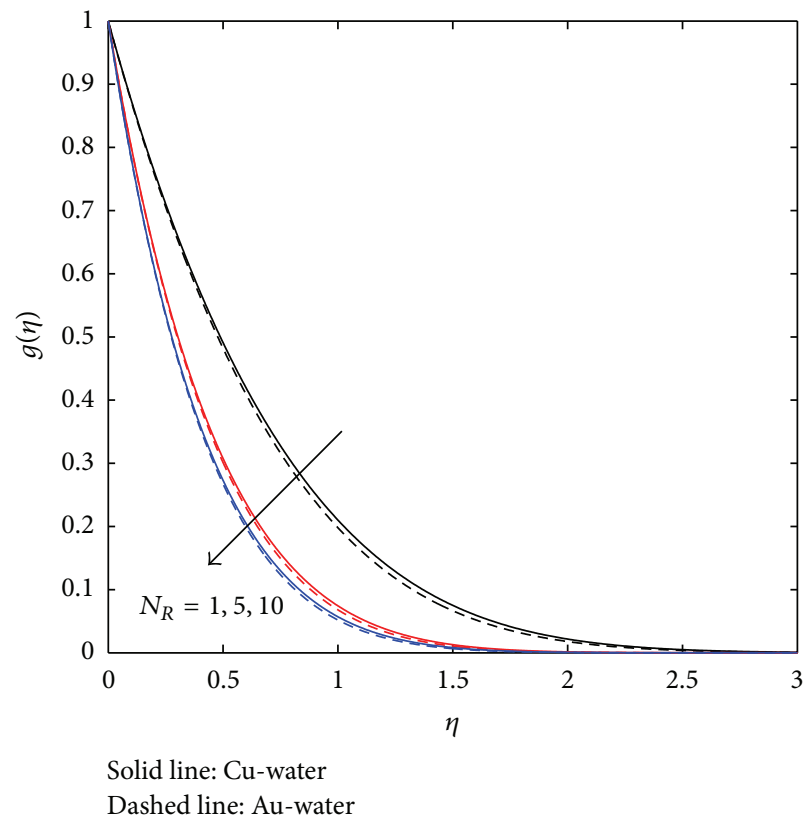

FIGURE 13: Effects of thermal radiation $N_{R}$ on temperature, when $f_{w}=1, \mathrm{Sc}=1.5, \phi=0.1$, and $\mathrm{Bi} \rightarrow \infty$.

\section{Acknowledgment}

The authors wish to thank the University of KwaZulu-Natal for financial support.

\section{References}

[1] H. Blasius, "Grenzschichten in Flssigkeiten mit kleiner Reibung," Zeitschrift Für Angewandte Mathematik Und Physik, vol. 56, pp. 1-37, 1908. 
[2] E. Pohlhausen, "Der Wrmeaustausch zwischen festen Krpern und Flssigkeiten mit kleiner Reibung und kleiner Wrmeleitung," Zeitschrift Für Angewandte Mathematik Und Mechanik, vol. 1, pp. 121-151, 1921.

[3] L. Howarth, "On the solution of the laminar boundary layer equations," Proceedings of the Royal Society of London A, vol. 164, pp. 547-579, 1938.

[4] A. M. M. Abu-Sitta, "A note on a certain boundary-layer equation," Applied Mathematics and Computation, vol. 64, no. 1, pp. 73-77, 1994.

[5] L. Wang, "A new algorithm for solving classical Blasius equation," Applied Mathematics and Computation, vol. 157, no. 1, pp. $1-9,2004$.

[6] R. Cortell, "Numerical solutions of the classical Blasius flat-plate problem," Applied Mathematics and Computation, vol. 170, no. 1, pp. 706-710, 2005.

[7] B. C. Sakiadis, "Boundary-layer behaviour on continuous solid surfaces I: boundary-layer equations for two-dimensional and axisymetric flow," AIChE Journal, vol. 7, pp. 26-28, 1961.

[8] S. Mukhopadhyay, K. Bhattacharyya, and G. C. Layek, "Steady boundary layer flow and heat transfer over a porous moving plate in presence of thermal radiation," International Journal of Heat and Mass Transfer, vol. 54, no. 13-14, pp. 2751-2757, 2011.

[9] M. A. Hossain and H. S. Takhar, "Radiation effect on mixed convection along a vertical plate with uniform surface temperature," Heat and Mass Transfer/Waerme und Stoffuebertragung, vol. 31, no. 4, pp. 243-248, 1996.

[10] M. A. A. Hamad, M. J. Uddina, and A. I. M. Ismaila, "Radiation effects on heat and mass transfer in MHD stagnationpoint flow over a permeable flat plate with thermal convective surface boundary condition, temperature dependent viscosity and thermal conductivity," Nuclear Engineering and Design, vol. 242, pp. 194-200, 2012.

[11] N. P. Singh, A. K. Singh, A. K. Singh, and P. Agnihotri, "Effects of thermophoresis on hydromagnetic mixed convection and mass transfer flow past a vertical permeable plate with variable suction and thermal radiation," Communications in Nonlinear Science and Numerical Simulation, vol. 16, no. 6, pp. 2519-2534, 2011.

[12] M. Z. Salleh, N. Mohamed, R. Khairuddin, N. S. Khasi'ie, R. Nazar, and I. Pop, "Free convection over a permeable horizontal flat plate embedded in a porous medium with radiation effects and mixed thermal boundary conditions," Journal of Mathematics and Statistics, vol. 8, pp. 122-128, 2012.

[13] E. Magyari, "Comment on 'A similarity solution for laminar thermal boundary layer over a flat plate with a convective surface boundary condition by A. Aziz, Comm. Nonlinear Sci. Numer. Simul. 2009; 14:10648', Communications in Nonlinear Science and Numerical Simulation, vol. 16, no. 1, pp. 599-601, 2011.

[14] J. H. Merkin and I. Pop, "The forced convection flow of a uniform stream over a flat surface with a convective surface boundary condition," Communications in Nonlinear Science and Numerical Simulation, vol. 16, no. 9, pp. 3602-3609, 2011.

[15] P. D. Weidman, D. G. Kubitschek, and A. M. J. Davis, "The effect of transpiration on self-similar boundary layer flow over moving surfaces," International Journal of Engineering Science, vol. 44, no. 11-12, pp. 730-737, 2006.

[16] S. U. S. Choi, "Enhancing thermal conductivity of fluids with nanoparticles," in Proceedings of the ASME International Mechanical Engineering Congress and Exposition, pp. 99-105, ASME, San Francisco, Calif, USA, 1995, FED231/MD66.
[17] H. Masuda, A. Ebata, K. Teramea, and N. Hishinuma, "Alteration of thermal conductivity and viscosity of liquid by dispersing ultra-fine particles," Netsu Bussei, vol. 4, pp. 227-233, 1993.

[18] S. K. Das, N. Putra, P. Thiesen, and W. Roetzel, “Temperature dependence of thermal conductivity enhancement for nanofluids," Journal of Heat Transfer, vol. 125, no. 4, pp. 567-574, 2003.

[19] B. C. Pak and Y. I. Cho, "Hydrodynamic and heat transfer study of dispersed fluids with submicron metallic oxide particles," Experimental Heat Transfer, vol. 11, no. 2, pp. 151-170, 1998.

[20] Y. Xuan and Q. Li, "Investigation on convective heat transfer and flow features of nanofluids," Journal of Heat Transfer, vol. 125, no. 1, pp. 151-155, 2003.

[21] H. U. Kang, S. H. Kim, and J. M. Oh, "Estimation of thermal conductivity of nanofluid using experimental effective particle volume," Experimental Heat Transfer, vol. 19, no. 3, pp. 181-191, 2006.

[22] V. Velagapudi, R. K. Konijet, and C. S. K. Aduru, "Empirical correlations to predict thermophysical and heat transfer characteristics of nanofluids," Thermal Science, vol. 12, no. 2, pp. 27-37, 2008.

[23] V. Y. Rudyak, A. A. Belkin, and E. A. Tomilina, "On the thermal conductivity of nanofluids," Technical Physics Letters, vol. 36, no. 7, pp. 660-662, 2010.

[24] N. Bachok, A. Ishak, and I. Pop, "Boundary layer flow over a moving surface in a nanofluid with suction or injection," Acta Mechanica Sinica, vol. 28, no. 1, pp. 34-40, 2012.

[25] J. H. Merkin, "A note on the similarity equations arising in free convection boundary layers with blowing and suction," Journal of Applied Mathematics and Physics, vol. 45, no. 2, pp. 258-274, 1994.

[26] V. Trisaksri and S. Wongwises, "Critical review of heat transfer characteristics of nanofluids," Renewable and Sustainable Energy Reviews, vol. 11, no. 3, pp. 512-523, 2007.

[27] X. Q. Wang and A. S. Mujumdar, "Heat transfer characteristics of nanofluids: a review," International Journal of Thermal Sciences, vol. 46, no. 1, pp. 1-19, 2007.

[28] J. A. Eastman, S. U. S. Choi, S. Li, W. Yu, and L. J. Thompson, "Anomalously increased effective thermal conductivities of ethylene glycol-based nanofluids containing copper nanoparticles," Applied Physics Letters, vol. 78, no. 6, pp. 718-720, 2001.

[29] N. Bachok, A. Ishak, and I. Pop :, "The boundary layers of an unsteady stagnation-point flow in a nanofluid," International Journal of Heat and Mass Transfer, vol. 55, pp. 6499-6505, 2012.

[30] N. Bachok, A. Ishak, and I. Pop, "Boundary layer stagnationpoint flow and heat transfer over an exponentially stretching/shrinking sheet in a nanofluid," International Journal of Heat and Mass Transfer, vol. 55, pp. 8122-8128, 2012.

[31] N. Bachok, A. Ishak, and I. Pop, "Flow and heat transfer characteristics on a moving plate in a nanofluid," International Journal of Heat and Mass Transfer, vol. 55, pp. 642-648, 2012.

[32] N. Bachok, A. Ishak, and I. Pop, "Unsteady boundary-layer flow and heat transfer of a nanofluid over a permeable stretching/shrinking sheet," International Journal of Heat and Mass Transfer, vol. 55, pp. 2102-2109, 2012.

[33] N. Bachok, A. Ishak, and I. Pop, "Flow and heat transfer over a rotating porous disk in a nanofluid," Physica B, vol. 406, no. 9, pp. 1767-1772, 2011.

[34] N. Bachok, A. Ishak, and I. Pop, "Stagnation-point flow over a stretching/shrinking sheet in a nanofluid," Nanoscale Research Letters, vol. 6, p. 623, 2011. 
[35] N. Bachok, A. Ishak, and I. Pop, "Boundary-layer flow of nanofluids over a moving surface in a flowing fluid," International Journal of Thermal Sciences, vol. 49, no. 9, pp. 1663-1668, 2010.

[36] N. Bachok, A. Ishak, R. Nazar, and I. Pop, "Flow and heat transfer at a general three-dimensional stagnation point in a nanofluid," Physica B, vol. 405, no. 24, pp. 4914-4918, 2010.

[37] R. K. Tiwari and M. K. Das, "Heat transfer augmentation in a two-sided lid-driven differentially heated square cavity utilizing nanofluids," International Journal of Heat and Mass Transfer, vol. 50, no. 9-10, pp. 2002-2018, 2007.

[38] H. C. Brinkman, "The viscosity of concentrated suspensions and solutions," The Journal of Chemical Physics, vol. 20, no. 4, pp. 571-581, 1952.

[39] J. C. Maxwell-Garnett, "Colours in metal glasses and in metallic films," Philosophical Transactions of the Royal Society A, vol. 203, pp. 385-420, 1904.

[40] C. A. Guérin, P. Mallet, and A. Sentenac, "Effective-medium theory for finite-size aggregates," Journal of the Optical Society of America, vol. 23, no. 2, pp. 349-358, 2006.

[41] H. F. Oztop and E. Abu-Nada, "Numerical study of natural convection in partially heated rectangular enclosures filled with nanofluids," International Journal of Heat and Fluid Flow, vol. 29, no. 5, pp. 1326-1336, 2008.

[42] Z. Alloui, P. Vasseur, and M. Reggio, "Natural convection of nanofluids in a shallow cavity heated from below," International Journal of Thermal Sciences, vol. 50, no. 3, pp. 385-393, 2011.

[43] A. Aziz, "A similarity solution for laminar thermal boundary layer over a flat plate with a convective surface boundary condition," Communications in Nonlinear Science and Numerical Simulation, vol. 14, no. 4, pp. 1064-1068, 2009.

[44] A. Ishak, "Similarity solutions for flow and heat transfer over a permeable surface with convective boundary condition," Applied Mathematics and Computation, vol. 217, no. 2, pp. 837$842,2010$.

[45] F. M. Hady, F. S. Ibrahim, S. M. Abdel-Gaied, and M. R. Eid, "Radiation effect on viscous flow of a nanofluid and heat transfer over a nonlinearly stretching sheet," Nanoscale Research Letters, vol. 7, p. 229, 2012. 


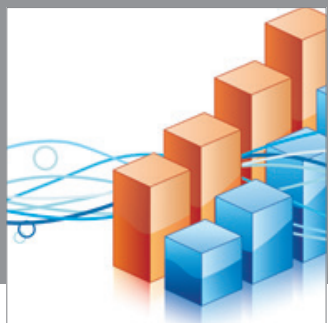

Advances in

Operations Research

mansans

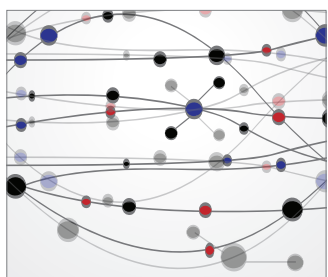

The Scientific World Journal
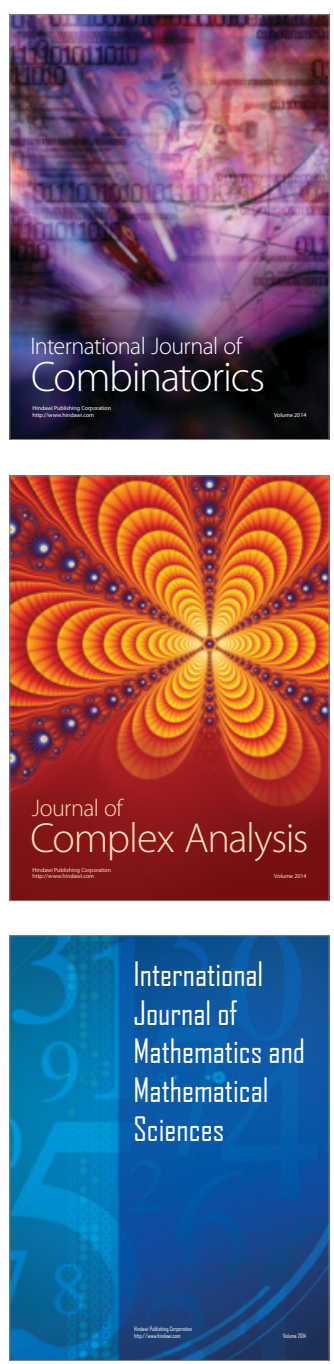
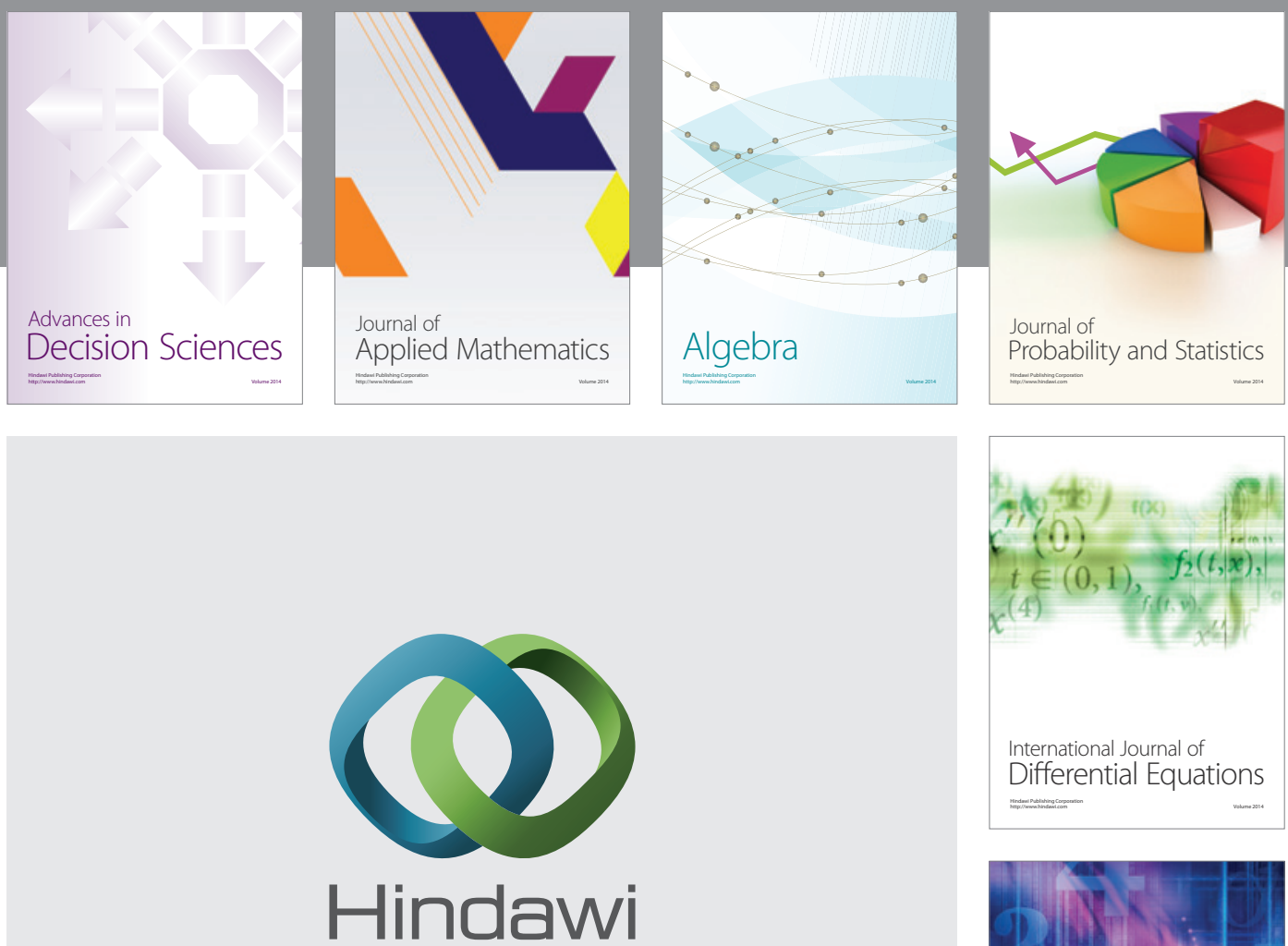

Submit your manuscripts at http://www.hindawi.com
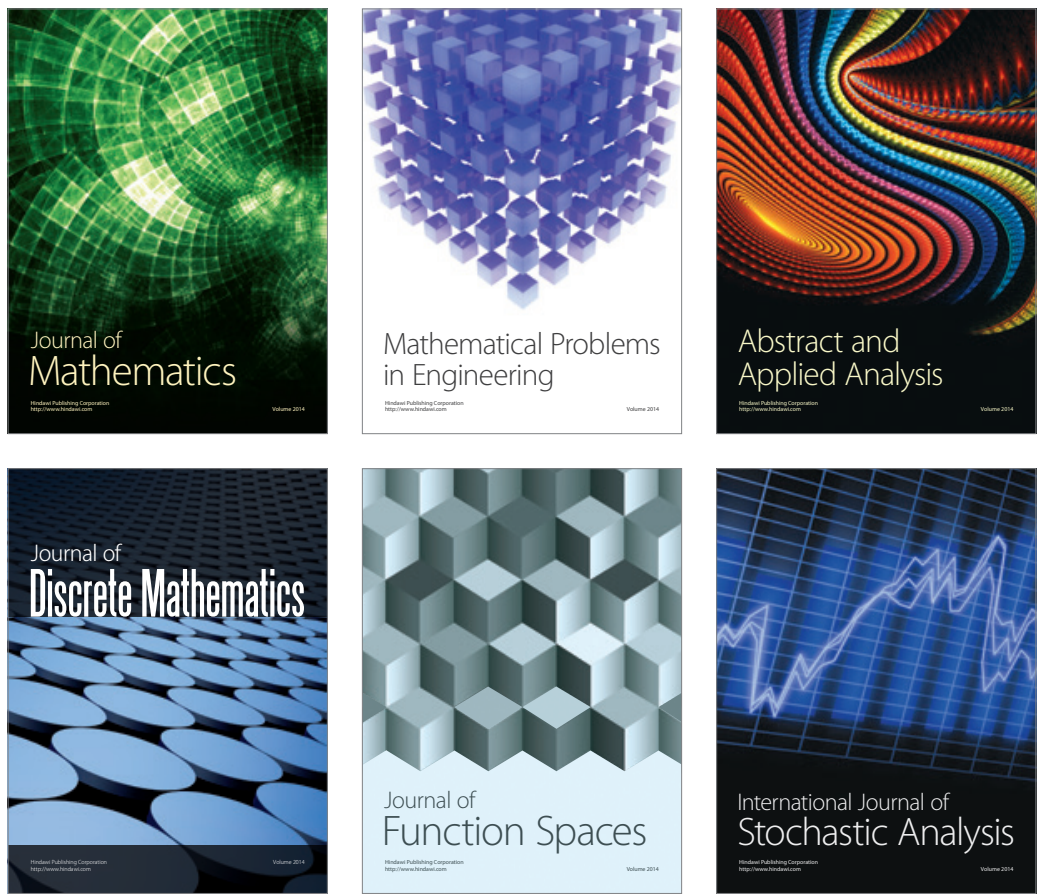

Journal of

Function Spaces

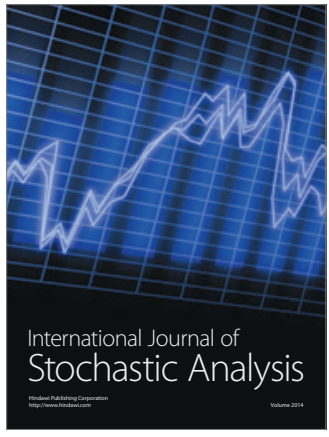

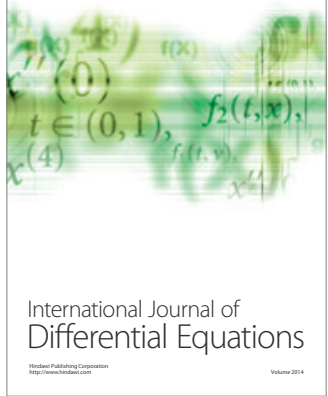
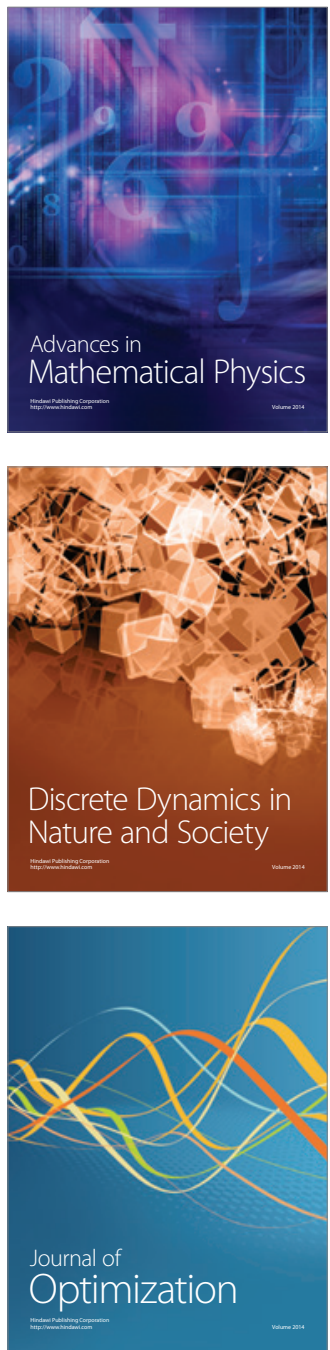